\title{
Benign postpartum pleural effusion
}

\author{
K.I. Gourgoulianis*, A.H. Karantanas*, G. Diminikou**, P.A. Molyvdas*
}

\begin{abstract}
Benign postpartum pleural effusion. K.I. Gourgoulianis, A.H. Karantanas, G. Diminikou P.A. Molyvdas. @ ERS Journals Ltd 1995.

ABSTRACT: The conditions of labour appear to favour the development of pleural effusion. The frequency of postpartum pleural effusion was investigated in this study using thoracic ultrasonography. Thirty one postpartum and 22 healthy nonpregnant women of the same age-group were examined, both supine and seated, via an intercostal approach.

Seven of the $31(23 \%)$ postpartum women had pleural effusion within 1-24 h of normal delivery. None of the nonpregnant women had pleural effusion. No correlation was found between postpartum pleural effusion and age, weight-gain during pregnancy, duration of labour, use of intravenous fluid, or oxytocin administration.
\end{abstract}

Pleural effusion seems to be a common finding postpartum, but of no clinical significance.

Eur Respir J., 1995, 8, 1748-1750.

\author{
*Dept of Physiology, Medical School, \\ University of Thessaly, Larissa, Greece. \\ **General Hospital of Larissa, Larissa, \\ Greece. \\ Correspondence: K.I. Gourgoulianis \\ Medical School \\ University of Thessaly \\ 22 Papakyriazi \\ 41222 Larissa \\ Greece \\ Keywords: Delivery \\ labour \\ pleural effusion
}

Received: January 291995

Accepted after revision July 101995
The conditions of labour appear favourable for the development of pleural effusion. Normal pregnancy could promote transudation of fluid into the pleural space because of the increased hydrostatic pressure of systemic circulation, the increased blood volume, and the decreased colloid osmotic pressure [1]. The repeated Valsalva manoeuvres may further promote pleural effusion because of the increased intrathoracic pressure and impaired lymphatic drainage of the pleural space, through elevation of systemic venous pressure. Atelectasis from the gravid uterus could also promote pleural fluid formation [2, 3]. The value of sonography for the detection of pleural fluid is well-known [4].

The purpose of this study, was the detection of pleural fluid after an uncomplicated labour, using thoracic ultrasonography, and the relationship of pleural effusion with the parameters of pregnancy and delivery.

\section{Patients and methods}

The study included 31 postpartum women and 22 healthy, nonpregnant women (control group) all of Greek origin, who agreed to have an ultrasound scan of their chest. All women were of the same age-group (18-31 yrs). Patient selection was entirely a matter of convenience, depending mainly on the time and day of delivery. The intervals between delivery and scan ranged 1-24 h, but most were less than $12 \mathrm{~h}$. All 31 postpartum women delivered normally, vaginally without any complications.

The examinations were performed using an Aloca SSD-650 ultrasound machine with $3.5 \mathrm{MHz}$ convex transducer.
The women under study were examined, both supine and seated, via an intercostal approach. Note was made of the presence of any septal or focal echoes within the collection, and of any associated pleural thickness or nodules. The amount of pleural fluid was subjectively categorized as small (a few $\mathrm{mL}$, depth less than $1 \mathrm{~cm}$ ), moderate $(2-3 \mathrm{~cm}$ depth), and large (depth more than 4 $\mathrm{cm})$. The sonograms were recorded on Polaroid film. The echogenicity of bile in the gall-bladder was used as a reference standard for anechoic fluid.

Statistical analysis was performed with Chi-squared method using a personal computer.

\section{Results}

All the fluid collections were well-defined anechoic areas within the pleural space on the right side. No pleural thickness, septa, or nodules were observed. Seven of the 31 postpartum women $(23 \%)$ had pleural effusion 1-24 h after delivery. None of the nonpregnant women of the control group had pleural effusion $(\mathrm{p}<0.001)$.

No correlation was found between postpartum pleural effusion and clinical features, such as age, weight-gain during pregnancy, duration and difficulty of labour, use of intravenous fluids after oxytocin administration. The presence of pleural effusion was asymptomatic in all women (table 1). Three of the seven women had moderate pleural effusion (including one woman with twins who had moderate effusion $3 \mathrm{~h}$ after vaginal deli-very), and four women had small effusion. None of the women had other complications, such as pre-eclampsia, pulmonary emboli or cardiomyopathy. 
Table 1. - Characteristics of pregnant women

\begin{tabular}{lll}
\hline & \multicolumn{3}{c}{ Pleural effusion } \\
& No & Yes \\
\hline Mean age yrs & 25 & 29 \\
Smoking in the pregnancy \% & 17 & 14 \\
Weight gain during pregnancy kg & 11.8 & 10.3 \\
Mean duration of pregnancy weeks & 39.8 & 38.9 \\
Mean duration of delivery h & 4.8 & 4.7 \\
Oxytocin administration \% & 83 & 71 \\
Mean fluid administration $\mathrm{mL}$ & 542 & 500 \\
\hline
\end{tabular}

\section{Discussion}

In the present study, ultrasound scans of the chest performed within $24 \mathrm{~h}$ of vaginal delivery, showed right pleural effusion in about one out of four women. The presence of postpartum pleural effusion did not correlate with clinically significant postpartum characteristics.

HESSEN [5] reported the first study that detected postpartum pleural effusions in $23 \%$ of women after delivery. All women underwent evaluation with chest radiographs in the lateral decubitus and Trendelenburg's position. Hughson et al. [6] showed that 20 out of 30 women had pleural effusion noted on chest radiograph, within $24 \mathrm{~h}$ of normal vaginal delivery.

A study by STARK and Pollack [3] restrospectively reviewed chest radiographs performed within $48 \mathrm{~h}$ of labour in women being evaluated for fever or respiratory symptoms, and found that 44 of the 45 women had evidence of small pleural effusions. Their study, which found a high frequency of postpartum pleural effusions, has used sensitive but nonspecific radiographic criteria and was not retricted to normal labours. In fact, there was a bias against normal labour, since the women were symptomatic.

The chest radiographs without decubitus views have a low specificity for the detection of pleural effusion, and they also imply an unnecessary radiation risk factor [7]. UDESHI et al. [8], examined 50 women with thoracic ultrasonography. In contrast to our finding, they found that only one women had evidence of pleural effusion. This patient had severe pre-eclampsia complicated by pulmonary oedema.

The main reason for the discrepancies of the above studies is the method of detection of pleural effusion. Sonography provides a rapid and convenient method for detecting the presence of pleural fluid $[9,10]$. The absence of septation or echogenicity suggests the presence of transudate [11]

In the pleural space, the liquid filtered by parietal pleura capillaries is absorbed into the visceral pleura capillaries $[12,13]$. At any time, the interstitial liquid content of the pleural space is the result of continuous dynamic phenomena involving the systemic and pulmonary circulations, lymphatic drainage, and the mechanical action of the chest cage. During the normal pregnancy an increased blood volume and a decreased colloid osmotic pressure could promote transudation of low protein fluid into the pleural space through combined hydrostatic and oncotic effects $[14,15]$.
Respiratory and circulatory movements help drainage of fluid through the pleurolymphatic communications. The gravid uterus decreases the movement of the diaphragm in the pregnant women, especially in the third trimester of gestation. There are regional differences in pleural liquid pressure among various pleural compartments. When compared to costal values, pleural liquid pressure is more subatmospheric over the fissures and, even more so, on the cardiac surface. Pregnancy alters this normal nonuniformity of pleural liquid pressure and may promote the accumulation of pleural fluid $[16,17]$. Normally, pleural liquid is absorbed into lymphatics. Emptying of the lymphatic into the circulation is impaired during systemic venous hypertension. Additionally, repeated Valsalva manoeuvres of parturition increase intrathoracic pressures and decrease lymphatic drainage $[18,19]$. The true incidence of benign postpartum pleural effusions in women undergoing normal labour, is about $25 \%$. Postpartum effusions are not clinically significant, but should be included in the differential diagnosis of pleural diseases occurring in the postparum period.

Aknowledgements: The authors wish to thank Ch. Ziogas Dept of Obstetrics and Gynecology, Larissa General Hospital, Greece, for support and encouragement.

\section{References}

1. Lai-Fook SJ. Mechanics of the pleural space: fundamental concepts. Lung 1987; 165: 249-267.

2. Heffner JE, Sahn SA. Pleural disease in pregnancy. Clin Chest Med 1992; 13: 667-678.

3. Stark P, Pollack MS. Pleural effusions in the postpartum period. Radiology 1986: 26: 471-475.

4. Mc Loud TC, Flower CDR. Imaging the pleura: sonography, CT and MR imaging. Am J Roentrenal 1991; 156: $1145-1153$.

5. Hessen I, Roentgen examination of pleural fluid. Acta Radiol 1951; 86: (Suppl.) 62-64.

6. Hughson WG, Friedman PJ, Feigin DS, Resnick R, Uoser KM. Postpartum pleural effusion: a common radiologic finding. Ann Intern Med 1982; 97: 856-858.

7. Fibenberger KL, Dock WI, Amman ME, Dorffner R, Hormann MF, Grabenwoger F. Quantification of pleural effusions: sonography versus radiography. Radiology 1994; 191: 681-684.

8. Udeshi UL, Mc Hugo JM, Crawford JS. Postpartum pleural effusion. Br J Obstet Gynaecol 1988; 95: 894-897.

9. Lipscomb DJ, Flower CDR, Hadfield JW, Ultrasound of the pleura: an assessment of its clinical value. Clin Radiol 1981; 32: 289-290.

10. Yang PC, Luh KT, Chang DB, Wu HD, Yu GJ, Kuo $\mathrm{SH}$. Value of sonography in determining the nature of pleural effusion: analysis of 320 cases. Am J Roentrenal 1991: 159; 29-33.

11. Lomas DJ, Padley SG, Flower CDR. The sonographIC appearance of pleural fluid. $B r J$ Radiol 1993; 66: 619-624.

12. Sah SA. State of the art: the pleura. Am Rev Respir Dis 1988: 138: 183-234.

13. Wiener-Kronish JP, Broaddus VC. Interrelationship of pleural and pulmonary interestitial liquid. Ann Rev Physiol 1993; 55: 209-226. 
14. Pistoleci M, Miniati M. Griuntini C. Pleural liquid and solute exchange: state of the art. Am Rev Resp Dis 1989; 140: 825-847.

15. Broaddus VC, Araya M. Liquid and protein dynamics using a new minimally invasive pleural catheter in rabbits. J Appl Physiol 1992; 72: 851-857.

16. Lai-Fook SJ, Rodarte JR. Pleural pressure distribution and its relationship to lung volume and interstitial pressure. J Appl Physiol 1991; 70: 967-978.
17. Agostoni E, Zocchi L, Agostoni PG. Pleural liquid pressure at the caudal border of the lung. Respir Physiol 1989; 75: 117-128.

18. Lai-Fook SJ, Kaplowitz MR. Pleural protein concentration and liquid volume in spontaneously hypertensive rats. Microvasc Res 1988; 35: 101-108.

19. Agostoni E, Zocchi L, Agostoni PG, Macklem PT. Pleural pressure from abdominal to pulmonary rib cage: sweep of the lung border. Respir Physiol 1989; 75: 107-117. 